\title{
Precariedad, materia en deterioro y subjetividades destituidas: acerca de una «estética de la descomposición» en dos documentales de Heddy Honigmann
}

Precariousness, Deteriorating Matter and Dispossessed Subjectivities: On the «Aesthetics of Decomposition» in Two Documentaries by Heddy Honigmann

Talía Dajes, PhD en estudios hispánicos por la Universidad de Michigan, es profesora de literatura y cultura latinoamericana contemporánea en la Universidad de Utah. Su investigación analiza las conexiones entre estética, memoria e historia en la producción cultural relacionada con la violencia política, con un enfoque en el cine peruano y de la región andina. Ha publicado sobre documental, cultura visual, cine y posconflicto, performance, y poesía de mujeres militantes 



\title{
Precariedad, materia en deterioro y subjetividades destituidas: acerca de una «estética de la descomposición» en dos documentales de Heddy Honigmann Precariousness, Deteriorating Matter and Dispossessed Subjectivities: On the «Aesthetics of Decomposition» in Two Documentaries by Heddy Honigmann
}

\author{
Talía Dajes Kaufman \\ Universidad de Utah, EE. UU. \\ t.dajes@utah.edu \\ Recibido: 11-06-2019 / Aceptado: 10-09-2019 \\ https://doi.org/10.1880o/conexion.201902.002
}

\section{PALABRAS CLAVE / KEYWORDS}

Documental, Perú, Heddy Honigmann, materialidad, precariedad, subjetividad / Documentary, Peru, Heddy Honigmann, materiality, precariousness, subjectivity

\section{RESUMEN}

Este ensayo se aproxima al trabajo de la documentalista peruano-holandesa Heddy Honigmann a través de dos de sus producciones - Metal y melancolía (1994) y El olvido (2008) -, situadas en Lima y centradas en la precaria subsistencia de sus personajes. El texto plantea una interpretación de sus respectivas propuestas visuales partiendo de la conceptualización de una «estética de la descomposición», es decir, de la puesta en escena de objetos en proceso de desgaste. Al apuntar la cámara hacia estos, la directora expone las circunstancias económicas y políticas que llevaron a la progresiva desintegración de las condiciones de vida individuales y colectivas, así como a la erosión de los beneficios de los que gozaban las clases medias en el Perú. Centrándose en la materialidad de los objetos en deterioro, este trabajo propone conectar el enfoque de Honigmann con los efectos de la implementación del neoliberalismo en un tipo de subjetividad paradigmática que podría concebirse como destituida.

\section{ABSTRACT}

This essay approaches the work of Peruvian-Dutch documentarian Heddy Honigmann by analyzing two of her films $-M e$ tal and Melancholy (1994) and Oblivion (2008)-, both set in Lima and centered on the precarious survival of its subjects. The text proposes to interpret each documentary's visual language as the embodiment of what could be conceptualized as an «aesthetics of decomposition», that 
is, the on-screen placement of objects undergoing a process of decay. I argue that, by pointing the camera toward these, the director exposes the economic and political circumstances that led to the gradual disintegration of individual and collective life conditions, as well as the erosion of the benefits previously enjoyed by middle class populations in Peru. By concentrating on the materiality of deteriorating objects, this article aims to connect Honigmann's viewpoint with the effects that the implementation of neoliberalism may have over a paradigmatic subjectivity that can be conceived as dispossessed.

\section{Precariedad, materia en deterioro y subjetividades destituidas: acerca de una «estética de la descomposición» en dos documentales de Heddy Honigmann}

En una de las escenas que abren Metal y melancolía (1994) -documental de la realizadora peruano-holandesa Heddy Honigmann (Lima, 1951) que se aproxima a las historias de diversos taxistas, hombres y mujeres, en la ciudad de Lima-, la directora entabla una conversación con uno de los conductores junto al viejo automóvil que utiliza para hacer taxi. Acerca de este, el taxista explica los mecanismos y particularidades que hacen que lo califique de «inrobable». Si bien este adjetivo podría describir un auto que posee los más avanzados dispositivos de seguridad, lo que revela la escena es todo lo contrario: un vehículo tan maltrecho y destartalado que encontrarle un aspecto positivo -el hecho de que nadie se lo quiera robar- resulta irónico.

El encuadre inicial muestra en primer plano el vidrio semirreventado del parabrisas que lleva a cuestas la calcomanía de taxi para luego hacer un barrido y enfocarse en el capó levantado, la oxidada carrocería expuesta y una galonera desde la que el taxista vierte agua al radiador descompuesto, tarea que, según este confiesa luego, debe realizar cada 30 cuadras. A las explicaciones del chofer sobre el particular funcionamiento de la puerta, la maletera, la chapa de arranque y otros componentes de su auto, se yuxtaponen imágenes de los forros ajados de los asientos, del exterior despintado y corroído, del parachoques hundido, entre otras, para dar cuenta de un proceso de deterioro imparable que se debe, sin duda, al paso del tiempo, al embate de la humedad limeña y a la imposibilidad de darle mantenimiento al auto por las condiciones materiales en las que se encuentra su dueño. Estas se hacen palpables en un detalle que emerge al final de la escena ante una intervención de la directora. «¿Cuál es tu trabajo?», pregunta Honigmann, a lo que el taxista contesta: «Yo trabajo en propaganda médica. Yo generalmente trabajo con mi corbatita y... y mi maletín»; así se plantea un contraste entre la escena y la pulcritud sugerida por su afirmación final. Será este, además, el punto de partida que dejará en claro que conducir un taxi no es más que un medio de subsistencia contingente. El 
fundido a negro posterior, que dará paso al título, genera una pausa para considerar este último fragmento de diálogo como indicador de una de las temáticas recurrentes en la narrativa del documental: la de la supervivencia. Esta no solo formará parte del discurso de los taxistas entrevistados, sino que dará pie a una reflexión acerca de las condiciones de precariedad que atraviesan.

Dichas condiciones no son producto del azar o de las decisiones personales de los conductores elegidos para el documental, sino, más bien, de una coyuntura particular: específicamente, se derivan de la crisis que se vivía en el Perú entre fines de la década de los ochenta e inicios de los años noventa. El primer gobierno de Alan García (1985-1990) había dejado una estela de hiperinflación que, junto con el pánico financiero por una posible estatización de la banca y la falta de inversiones provocada por el conflicto armado interno iniciado en 1980, generaron una situación alarmante para la economía nacional ${ }^{1}$. Con una recesión incesante entrada ya la década de los noventa, durante la gestión inaugural de Alberto Fujimori (1990-1995) se impulsaron proyectos de ley que, bajo una lógica neoliberal, fomentaron la privatización de empresas públicas, desregularon el mercado y flexibilizaron el trabajo. Para plantear la relación entre el contexto sociopolítico peruano y los sujetos del documental, la directora se posiciona dentro de la narrativa, la mayoría de las veces, como una pasajera en cada uno de los taxis a cuyos conductores entrevista. Si bien esto se configura como su lugar de enunciación, en su rol como documentalista Heddy Honigmann aparece como una figura con cierto grado de distancia ante aquello que explora frente a la cámara. A pesar de haber nacido y haberse criado en Lima, Honigmann partió del Perú para estudiar cine en Roma y se afincó luego en Ámsterdam, donde conseguiría la ciudadanía holandesa en 1978 (Mesquita Duarte, 2017, p. 61) y produciría la mayoría de su obra, la cual incluye cortos, largometrajes de ficción y documentales. A esto, y a su condición de hija de judíos inmigrantes sobrevivientes del Holocausto (Mesquita Duarte, 2017, p. 61), se debe que su cine haya sido definido como el de una outsider (Beerekamp, 2012) cuya mirada, externa y con cierta distancia, no puede sino cuestionar aquello que registra.

Este afán crítico se hace evidente tanto en Metal y melancolía como en un documental posterior, El olvido (2008), el cual puede considerarse como la segunda parte de un díptico que complementa al primero, ya que ambos se sitúan en Lima y se centran en la precaria subsistencia de los sujetos que presentan. En el caso de $\mathrm{El} \mathrm{ol-}$

\footnotetext{
${ }^{1}$ Una explicación exhaustiva de las causas, consecuencias y condiciones detrás del conflicto desencadenado por la guerra que declaran al Estado organizaciones políticas subversivas como el Partido Comunista del Perú Sendero Luminoso (PCP-SL) y el Movimiento Revolucionario Túpac Amaru (MRTA) se encuentra en el Informe Final de la Comisión de la Verdad y Reconciliación (2003).
} 
vido, se trata de una mezcla de artistas callejeros, vendedores ambulantes, artesanos, mozos y otros trabajadores del sector de servicios. Ambas películas se configuran como hitos de un intervalo temporal (1994-2008) en el que se transita desde la promesa del neoliberalismo hasta su fracaso a través de la exposición de aquellas circunstancias económicas y políticas que llevaron a la progresiva desintegración de las condiciones de vida individuales y colectivas que afectó principalmente a las clases medias y populares del Perú. Partiendo de este planteamiento, la intención del presente ensayo es pensar la propuesta visual de Honigmann en estos dos documentales como la configuración de una «estética de la descomposición», es decir, como una puesta en escena de objetos -tales como los carros de los taxistas o la ropa de los artistas callejeros, por ejemplo- que se encuentran en proceso de desgaste. El motivo recurrente del deterioro aparecerá entonces como seña de la progresiva desarticulación del cuerpo político y social, producto de las medidas neoliberales implementadas en la década de los noventa en respuesta a la crisis. Este trabajo intentará explorar, a través de la materialidad, una relación entre los objetos en deterioro, el neoliberalismo y el tipo de subjetividades paradigmáticas que este produce.
Tal como lo sugiere Héctor Hoyos (2016), aproximarse a esta problemática supone «constatar las estrechas relaciones entre globalización y cultura material» (p. 255), especialmente desde el auge de la primera, cuyo inicio se ubica en 1989 -con la caída del muro de Berlín-, y, con ello, la entrada de un «nuevo régimen en nuestra relación con los objetos» (Hoyos, 2016, p. 255). Por su parte, Jane Bennett (2015) se posiciona desde el pensamiento identificado como «nuevo materialismo» para plantear la existencia de una agencia de los objetos, a los cuales considera inseparables de los fenómenos y comportamientos humanos, con el término vital materialism. Este materialismo vital, el cual es potenciado por la concentración de riqueza en el contexto de las economías neoliberales, puede definirse como una forma de reconocimiento de los objetos a partir de su aspecto relacional y productor de significado. Asimismo, el reciente interés por pensar críticamente el rol de los objetos y la mercancía se deriva de una renovación del análisis marxista (Bennett, 2015, p. 223). Pero, incluso antes de la consolidación de corrientes filosóficas como esta, el reconocimiento de la vitalidad de los objetos podía encontrarse en autores como Spinoza, o Deleuze y Guattari². Ya en 1986, Arjun Appadurai consignaba en su introducción a The Social Life

\footnotetext{
${ }^{2}$ Al referirse a estos autores, Bennett clasifica al pensamiento de Spinoza como influido por corrientes filosóficas que consideran al universo un ente sensible y en constante evolución, especialmente cuando se toma en cuenta su noción de conato, es decir, aquel impulso por el cual todo cuerpo busca alianzas para aumentar su vitalidad (p. 224). Por su parte, Deleuze y Guattari exploran las conexiones heterogéneas entre cosas, lugares y personas para formar una conciencia expandida que incluye a la materia como viva y en movimiento (Bennett, 2015, p. 226).
} 
of Things una reflexión acerca del valor de las cosas en tanto bienes de consumo e intercambio, puntualizando el hecho de que estos «constantly spill beyond the boundaries of specific cultures (and thus of specific regimes of value)» (p. 57). Tal exceso parece requerir una agencia por parte de lo material más allá de los intercambios humanos, en este caso, sobre el control político que se ejerce en la demanda (p. 57). Aunque Appadurai no profundiza en este aspecto, es posible vislumbrar el germen de esta idea en su afirmación. Así, una reconsideración de la materia -tradicionalmente vista como inerte o como recipiente vacío a la espera del aporte humano- desde su condición vital rechaza lo que Timothy Morton (2016) define como "the rigid distinction between person and thing» (p. 167), sobre la que se asienta la frontera entre lo humano y aquello que no lo es. 0 , a decir de Bennett, se trata de la comprensión de un mundo «populated not by active subjects and passive objects but by lively and essentially interactive materials, by bodies human and nonhuman» (p. 224) en el que estas materialidades, las cuales se encuentran cada vez más presentes - debido a una voluminosa proliferación de cosas para consumir, usar y tirar, característica del actual contexto cultural- demandan atención (p. 224).
Si bien en ambos documentales de Honigmann pueden percibirse los vínculos entre materialidad, neoliberalismo y globalización, así como esa «llamada de atención» proveniente de la propagación de objetos deteriorados en pantalla, esta particularidad -su desgaste- produce también aquellos vacíos en los que se revela la precarización total de la vida. En este proceso, la precariedad no solo afecta a las condiciones de existencia, sino a la existencia misma; es decir, reduce la vida a sus posibilidades de supervivencia. En esta exposición a la vulnerabilidad más extrema -y no es casual aquí que Judith Butler (2006) relacione precariedad con vulnerabilidad-, tanto Metal y melancolía como El olvido hacen partícipe a su público de la construcción de algo que podría concebirse como una subjetividad destituida, cuyo sentido primario gira en torno a una vida desprovista de todo aquello que va más allá de la subsistencia biológica y signada por su relación con una materialidad en constante deterioro.

\section{Metal, melancolía y crisis}

Honigmann regresa a su país de origen dos décadas después de su partida para filmar su primer documental ambientado en Lima (Sesic, 2013, p. 369), Metal y melancolía ${ }^{3}$. Estrenada en 1994 -al año

\footnotetext{
${ }^{3}$ Según Godoy (2013), la filmación y estreno del documental de Honigmann en la década de los noventa coincide con los de otros realizadores peruanos que también radican en el extranjero (Juan Alejandro Ramírez, Mary Jiménez y Javier Corcuera). Como bien señala el autor, estos se ubican en un período de transición entre la derogación de la antigua ley de cine y la promulgación e implementación de una nueva (p. 129). Esto probablemente contribuyó a la ralentización de la producción local y a la apertura de salas y espacios de exhibición que fueron aprovechados por estas producciones cuyo contenido era reconociblemente nacional pero que llegaban de fuera.
} 
siguiente de aprobarse por referéndum la nueva Constitución promulgada por el gobierno de Fujimori luego del autogolpe de 1992-, la película da cuenta de un momento particular en el proceso de crisis política, económica y social que el Perú venía atravesando desde la década de los ochenta. Como se revela en la escena descrita al comienzo, un recurso habitual para complementar los salarios que cada vez alcanzaban para menos -o para conseguir un ingreso en caso de desempleoera el dedicarse a hacer taxi. Esta conexión la comenta el realizador Joel Calero (2011) ubicando la película en el contexto de la crisis y sus efectos sobre la movilidad social:

En los inicios de la década de los noventa la sociedad peruana estaba todavía aturdida por la hiperinflación desencadenada en el primer gobierno de Alan García, quinquenio en el que la clase media dejó de serlo para sumirse, con decrépita dignidad, en la pobreza (la hiperinflación, en 1989, llegó a picos de 2775\%). Tal vez por eso, en $\mathrm{M} \mathrm{y} \mathrm{m}$, la directora elige como personajes a profesionales que deberían haber pertenecido a esa casi extinta clase social y que hacen taxi para poder sobrellevar la crisis (párr. 6).

Este punto hace eco de la proliferación de imágenes de automóviles en la película -además de los taxis destacados- y de limeño. El tráfico crece exponencialmente con la desregulación total del sistema de transporte en la década de los noventa (Otra Mirada, 2013, p. 2) y, junto con la «liberalización de las rutas y la permisividad para comprar autos (y autopartes usadas)» (Otra Mirada, 2013, p. 3), los autos, especialmente los de segunda mano, empiezan a inundar la ciudad y crean un caos que hasta hoy permanece a pesar de recientes esfuerzos por desenmarañarlo. A esto es necesario agregar la informalidad en la que hasta el 2012, año en el que se concluye un proceso de formalización y registro (Otra Mirada, 2013, p. 5), se encontraba la labor de conducción de taxis. Para ejercerla, como muestra el documental, solo era necesario comprarle, por un sol, a uno de los tantos vendedores ambulantes que transita frente a la cámara, un letrero con la palabra taxi y adherirlo al parabrisas del auto.

Para subrayar los distintos ejes que convergen en esta coyuntura, en Metal y melancolía Honigmann pone un agudo énfasis visual en las superficies corroídas, descascaradas y viejas, inacabadas o con señales de abandono, cubiertas de polvo y suciedad, cuyo color se mimetiza con la niebla y contaminación de la ciudad. Este tipo de puesta en escena de objetos, y especialmente de vehículos, en descomposición encuentra un correlato en algunos documentales brasileños recientes, acerca de los cuales Gustavo P. Furtado (2016) realiza un incisivo análisis. En un paréntesis a su reflexión acerca de KFZ- 
1348 (2008) -ópera prima de Marcelo Pedroso y Gabriel Mascaro que, precisamente, toma su nombre de la placa de un auto de 1965 hallado en un basural (p. 123) -, Furtado subraya la necesidad de distinguir entre las categorías de "cosa» $\mathrm{y}$ «objeto», ya que esta última implica la existencia de un sujeto usuario que le da significado (p. 124). Sin embargo, cuando los objetos son abandonados, desechados, quedan arruinados - lo que Furtado llama «objetos-en-ruina»- o son olvidados por el sujeto que originalmente los infundió de significado, estos se revierten nuevamente a su condición de «cosa» (p. 124). No obstante, y a contrapelo de esta operación, en el documental de Honigmann esta reversión no ocurre, puesto que los autos continúan desempeñando sus funciones aún como objetos-en-ruina, ya deteriorados y pasada su fecha de caducidad. Sus dueños los conducen más allá de su proceso de devaluación y se constituyen, a través de la propia materia descompuesta, en crítica de una temporalidad moderna que privilegia la renovación e impone el consumo constante.

Aquí los sujetos no abandonan ni olvidan a los objetos. Más bien, mantienen su vínculo con ellos y, en consecuencia, con su significado; extienden su vida de uso sin importar su nivel de desgaste. Es a partir de aquel lazo entre objeto y sujeto que en el documental se teje el entramado de una subjetividad que no puede sino responder a las condiciones materiales que la rodean. La secuencia final del documental enfatiza la relación sujeto-objeto y la complica introduciendo además el aspecto afectivo. Utilizando como fondo musical una canción de amor que hace sonar en la radio de su auto uno de los taxistas, la cual le recuerda un romance de juventud, la escena realiza una transición hacia una serie de encuadres que funcionan como retratos de los taxistas que han aparecido en pantalla ${ }^{4}$. Cada uno presenta al conductor parado junto a su vehículo, estacionado en algún lugar de la ciudad, mientras que la canción expresa el amor sincero de un amante a su amada, lo que sugiere una conexión entre ambos que va más allá del simple valor de uso. Como objetos inanimados, el sentido y utilidad de los autos provienen de la actividad humana; sin embargo, a través de estas escenas finales, la película sugiere que estos -en particular, pero también la materia inerte en general- tienen la potencialidad de afectar al sujeto (Daly, 2018, p. 2). A través de la interacción entre sonido e imagen, el documental juega con la metáfora amorosa para crear un montaje en el que las fronteras entre lo humano y lo no humano se disipan.

Las historias que cuentan los taxistas en Metal y melancolía - las cuales son, principalmente, acerca de sus automóviles y el oficio de conducirlos- encuentran nodos en común con la tenue relación que establecen con los mecanismos de supervivencia en una ciudad que, al ser encua- 
drada por la cámara haciendo uso de los marcos de las ventanas, aparece siempre afuera, externa, lejana y, por lo mismo, amenazante. Al igual que el conductor del automóvil «inrobable», los demás taxistas mencionan también sus ocupaciones «reales» -en el sentido de que para estas se han preparado, mientras que el hacer taxi permanece como producto de la coyuntura-: actor, policía, incluso profesor de la Escuela de Oficiales de las Fuerzas Armadas, entre otras. A pesar de su diversidad, el punto que los une es que ninguna de ellas alcanza como medio de subsistencia, lo que abre el relato del documental hacia una doble reflexión sobre la precariedad. Por un lado, se revela el estado del mercado laboral formal para las clases medias y populares y la necesidad de recurrir al taxi para sobrevivir al embate de las reformas neoliberales de liberalización y desregulación; por el otro, se construyen subjetividades a partir de la interacción cotidiana con la materialidad de aquellos objetos que se resisten a dejar de serlo, es decir, que se resisten a volver a su estado anterior de «cosa». Si para el postulado cartesiano clásico («Pienso, luego existo») el sujeto funcionaba como productor de su propia realidad, esto es, de un tiempo y un espacio, Honigmann presenta aquí una operación, si no del todo inversa, definitivamente híbrida y relacional: es la realidad tangible que rodea constantemente a estos sujetos -es decir, los objetos-en-ruina de los que no pueden desprenderse y alrededor de los convierte en productora parcial de dichas subjetividades. Al poner en pantalla el sustento material de la precariedad -el óxido, la ruina, las roturas, los agujeros y los mecanismos total o parcialmente averiados-, la directora se enfoca en un proceso de construcción del ser que depende no de una esencia, sino de una existencia (Nancy, 1991, p. 6), en este caso, de una existencia-en-crisis. Esto se refleja en la escena en que se explica el origen del título del documental, cuando uno de los choferes recuerda la reflexión de un escritor acerca del carácter nacional. Aquí una serie de encuadres muestran las calles de Lima atestadas de vehículos, públicos y privados, en su mayoría viejos, lo que crea un caos visual y sonoro que se superpone a la voz en off del taxista:

Una vez leí que un famoso poeta español decía que el Perú estaba hecho de metal y melancolía [...] tal vez porque el dolor y la pobreza nos han vuelto duros, como la dureza de nuestros metales. Y melancolía porque también somos tiernos y añoramos tiempos mejores que se perdieron en el olvido.

La comparación entre una subjetividad creada por las duras condiciones de vida que trae consigo la pobreza y las características del metal -que no solo es rígido, sino que se desgasta y se corroe al quedar expuesto a ciertos elementos- se conjuga con la expresión de una interioridad desde la que es posible entrever un hori- 
zonte o incluso una promesa anclada en la eventualidad de que regresen, en el futuro, aquellos «tiempos mejores». Posibilidad que, como se verá a través del análisis de El olvido, los 14 años siguientes se encargarán de desmantelar.

\section{El olvido y la subjetividad destituida}

Acerca de El olvido, Jorge Ruffinelli (2009) destaca dos ejes que se hacen visibles en las historias de las personas que aparecen en el documental: la pobreza extrema y la dignidad (p. 174) a pesar del olvido al que son sometidas por mandatarios e instituciones estatales. Estas historias se enfocan en un conjunto de artistas callejeros, vendedores ambulantes, cantineros y meseros en el trajín diario entre la casa y el trabajo, intercalándose además con material de archivo de las juramentaciones durante las tomas de mando de algunos de los, hasta entonces, más recientes presidentes de la repúblicas ${ }^{5}$ Este dispositivo funcionará para plantear una relación entre pasado y presente que toma un carácter circular: mientras desde el poder se esgrimen las mismas promesas cada cinco años, la vida en las calles no mejora ni cambia para los ciudadanos de a pie. El Estado se convierte en uno de los agentes que potencia esa pobreza extrema, ante la que los afectados solo pueden oponer aquella dignidad que percibe Ruffinelli en las imágenes documentales de Honigmann. Si Metal y melancolía muestra una serie de retratos de vida acerca de las formas de sobrellevar una crisis que promete solucionarse por medio de la implementación de reformas neoliberales, El olvido se ubica al otro lado de esa promesa -frustrada, precisamente, para aquellos que más necesitan de su cumplimiento- poniendo en escena una serie de representaciones de lo precario como totalidad de la vida.

Si bien existe un entendimiento común acerca del concepto de lo precario en tanto relacionado con otras ideas como las de escasez, inseguridad y limitaciones materiales o económicas (Burucúa y Sitnisky, 2018, pp. 1-2), Butler (2006) profundiza en esta noción para revelar aristas poco consideradas. Una de estas es la vulnerabilidad como resultado de la exposición a la potencial violencia del otro, es decir, el reconocimiento de que la propia vida se encuentra siempre a merced de la voluntad del otro (pp. 28-29). Aunque, de cierto modo, esta vulnerabilidad forma parte intrínseca de la vida humana, ciertas circunstancias sociales y políticas la potencian, especialmente aquellas signadas por situaciones de violencia (p. 29). En estos casos, algunas vidas estarán más expuestas a la vulnerabilidad que otras, lo que constituye una especie de «jerarquía del dolor» (p. 32) que supone a unos más humanos que otros.

En las trayectorias que se trazan en $\mathrm{El} \mathrm{ol-}$ vido, será posible discernir esa vulnerabi-

${ }^{5}$ En el 2008 Alan García cumplía su segundo mandato (2006-2011), algo que se comenta en el documental: el barman caracteriza la elección entre aquel y su opositor, Ollanta Humala, como una entre «hepatitis B o sida». 
lidad generada por la violencia sistémica de un Estado que deja a toda una clase social desprovista de protección y apoyo. Nuevamente, el tráfico limeño tomará protagonismo, esta vez atravesado por malabaristas y acróbatas que aprovechan la luz roja para realizar sus actos y pedir propina a los conductores, así como fotógrafos callejeros, afiladores de cuchillos y vendedores ambulantes. Si bien la corrosión y la descomposición del metal automovilístico aparecen en pantalla, en la propuesta visual de este documental predominan las imágenes de otros materiales desgastados, tales como la ropa desteñida de los artistas callejeros, sus zapatos sucios y cubiertos de tierra o las paredes descascaradas de una casa humilde. Estos se presentan en un fuerte contraste con el colorido de las pelotas o las clavas con las que algunos hacen malabares, la pompa de las juramentaciones presidenciales, y una serie de escenas que ocurren en el interior de lujosos restaurantes y bares donde dan testimonio un mesero y un barman, respectivamente. La informalidad económica y la red de trabajos sobre los que esta se asienta se perfilan nítidamente en tanto vulnerabilidad y condición de precariedad por medio de diversas escenas que señalan hacia distintos aspectos de esta relación, así como a las subjetividades que produce. De hecho, Ruffinelli (2009) encuentra la clave del documental en una secuencia en la que Honigmann habla con el repujador de cuero Mauro Gómez, debido a que penetra, precisamente, en el terreno de la subjetividad (p. 176). De su his- toria, acerca de la pérdida casi total de su negocio durante la crisis económica de la década de los ochenta, Ruffinelli concluye que «él no es el ejemplo de la resignación sino del esfuerzo de sobrevivir dignamente» (p. 176), puesto que Gómez se enfoca en la alegría que le causa haberse recuperado y no en aquello que perdió (p. 177). Sin embargo, ese relato esperanzador que demuestra la entereza del personaje para sobrevivir gira, necesariamente, alrededor de la pérdida. Es decir, esta última es la condición fundacional de la que emerge la subjetividad en esta escena.

Dos escenas posteriores parecen seguir una progresión decreciente en cuanto a las expectativas sobre el porvenir. Si bien en una se reconocen visos de esperanza, la otra refleja el despojo total de esta, así como de cualquier posible futuridad. En la primera, Honigmann conversa con una familia de niñas acróbatas que realizan piruetas frente a los conductores. Ellas, sentadas en la vereda junto a su madre, María, le cuentan a la directora sus aspiraciones: ser «una artista olímpica de gimnasia» es el sueño de una de ellas. María menciona que tiene cinco hijos, pero que solían ser seis: una, la mayor, murió atropellada un año antes cuando trabajaba repartiendo sopa, exactamente en la misma intersección en la que se encuentran conversando. Los primeros planos de las caras que revelan gestos de tristeza dan paso a planos detalle de los pies sucios, semidescubiertos, sobre un suelo rugoso y mal pavimentado, lo que plantea una relación directa entre 
el sufrimiento de la familia por el fallecimiento de la hija y las condiciones de precariedad que las exponen al peligro de la muerte. El desgaste material parece ser aquí la única continuidad posible: se inicia en el ambiente que las rodea (la calle atestada de autos, con las pistas rotas y sin mantenimiento), se infiltra en aquello que las cubre (la ropa y sandalias viejas) y, finalmente, empieza a ocupar el espacio de la interioridad para jugar un rol en la conformación del yo. Lo que estas imágenes producen es una sensación de distancia insondable debida al contraste que se genera entre la esperanza olímpica de la niña y su experiencia vivida, configurada a partir de su relación con los materiales en descomposición. Es aquí donde puede hablarse de una «estética de la descomposición», en tanto que las imágenes recomponen en pantalla, para el espectador, aquello que los sujetos del documental experimentan a través de los sentidos.

En la segunda escena, Honigmann entabla una conversación con Henry, un adolescente piurano de 14 años que trabaja como lustrabotas y que migró a Lima para vivir con unos tíos mientras su familia se quedó en su tierra natal. Las preguntas que le plantea la documentalista parecen cotidianas, hasta casi estándar, podría decirse. Sin embargo, las respuestas parecen dislocar sus expectativas y, a su vez, las del público. Luego de afirmar que no va al cole- gio porque tiene que trabajar, Honigmann le pregunta si tiene recuerdos bonitos de algo. Ante la negativa de Henry, viene la repregunta: «¿Y recuerdos feos?». «Recuerdos feos... tampoco», contesta él, algo exasperado. Por último, la realizadora le pregunta si tiene sueños (refiriéndose a deseos por cumplir), a lo que el chico responde: «Casi no sueño. No sueño casi», claramente interpretando la pregunta como si aludiera a lo que el cerebro produce al dormir. Si bien se trata de una confusión, en este equívoco puede leerse la situación de Henry como una basada en la imposibilidad de contemplar siquiera la existencia de un horizonte hacia el cual dirigirse. Se trata, pues, de una ausencia de futuridad que revela, a su vez, la manera en que la vida ha sido reducida a mera supervivencia. El joven lustrabotas aparece entonces como un sujeto cuya propia noción de sí ha sido despojada de toda complejidad y sentido: no existe un pasado al cual asirse, ni una memoria desde la cual construirse, ni un futuro al cual proyectarse. En lugar de revelar la vida interior de Henry, la escena expresa más bien las tenues condiciones de la vida en el espacio y la temporalidad del capitalismo neoliberal, es decir, la subjetividad ya no simplemente construida a partir de su relación con lo material, sino convertida, en sí misma, en materia ${ }^{6}$.

Ambas escenas resultan paradigmáticas en cuanto al recorrido que realiza el do-

${ }^{6}$ Esta noción encuentra un correlato en el concepto propuesto por Walter Benjamin (y luego retomado por Giorgio Agamben) de nuda vida, central para el análisis de la biopolítica como mecanismo de poder. Al respecto, pueden consultarse Benjamin (2009) y Agamben (2013). 
cumental a través de la precariedad y de la vulnerabilidad. Estas aparecen no solo como resultado de condiciones económicas, sino que se configuran como el ensamblaje desde el cual se construyen las distintas subjetividades en pantalla, las cuales podrían clasificarse como «destituidas» en tanto que parten de la privación y se condicen con la materialidad de los objetos desgastados que se multiplican a su alrededor. Para el 2008 (año de estreno de El olvido), si bien el Perú había superado la crisis económica de la década de los noventa y había logrado procesar -al menos desde el ámbito oficial ${ }^{7}$ - las secuelas del conflicto armado interno, las medidas de privatización y desregulación habían sido parte de la política económica oficial de los Gobiernos que se sucedieron después del periodo fujimorista. Más allá de cualquier diferencia ideológica, se terminó por institucionalizar el neoliberalismo como modelo, ya que, hasta el momento, se había logrado una recuperación de la economía, al menos a nivel de indicadores macroeconómicos. Aun así, el documental parece reflejar una realidad desde la que es menos posible imaginar -e imaginarse en- un futuro mejor.

\section{Vida precaria y superficies en desgaste}

Butler (1997) apunta que el proceso de constitución del sujeto pasa necesariamente por el de la sujeción, es decir, aquello que subordina al sujeto al poder (p. 2). Esta relación supone entonces que el poder no solo actúa sobre el sujeto, sino que, de hecho, lo hace existir (p. 13). Sin embargo, si el poder que ejerce tal operación es inestable o se encuentra en crisis, ¿qué ocurre con la subjetividad a la que da forma? Metal y melancolía puede prestar una clave para indagar en esto. De cierto modo, en este documental la crisis se constituye en un momento de apertura en el que, si bien hay que luchar por sobrevivir en condición de precariedad, aún existe una promesa de transformación. Esa posibilidad, no obstante, aparece coartada en El olvido por una realidad determinada por lo dado, consecuencia que puede relacionarse directamente con la inserción del Perú en el mercado capitalista global y la consolidación del neoliberalismo como modelo.

Esto último parece reflejarse al final del documental. El olvido termina con un verso de un poema del escritor José Watanabe (1946-2007), a quien la película está dedicada: «En el horror solo me permito este poema silencioso». ¿A qué horror podría estar aludiendo Honigmann por medio de esta cita y por qué es uno que produce silencio? Si bien podría tratarse de «otra manera de mostrar los dos extremos de la realidad peruana: el horror y la poesía» (Ruffinelli, 2009, p. 177), antes de ensayar una respuesta alternativa cabría reflexionar acerca de las imágenes forme Final (2003), tres años después de lo que la periodización del conflicto considera su fin oficial (1980-2000). 
inmediatamente anteriores a la aparición del texto. Estas muestran a las niñas acróbatas realizando, una vez más, su acto callejero frente a los autos, ahora de noche. Después de pasar por las ventanas para recibir algunas monedas, regresan al lugar habitual de la vereda, junto a su madre. Aquí, el encuadre se congela y aparece el fragmento poético de Watanabe sobreimpuesto en la esquina en la que fue atropellada la hermana mayor de las niñas. Partiendo de esta secuencia final, sería posible postular que el horror proviene de la precarización de la vida que se produce debido a la visión neoliberal de esta, visión que efectivamente la silencia al reducirla a materia prima para la acumulación capitalista y al dejarla expuesta a ser corroída, desgastada, abandonada. Esto se condice con lo que Idelber Avelar (2009), en su lectura de ciertas novelas argentinas de posdictadura, concibe como «the commodification of every corner of social life» (pp. 191-192), es decir, la transformación del ámbito social en mera mercancía y su consiguiente influencia en la formación de la subjetividad dentro del régimen neoliberal.

A través de estos documentales, tanto por separado como en relación el uno con el otro, Heddy Honigmann invita al espectador a reflexionar acerca del pasado reciente en el Perú. Esta reflexión se configura en un doble registro. En primer lugar, un registro histórico que, en forma de díptico ubicado en un intervalo temporal, recoge la profunda transformación social que atravesó el Perú hacia el cambio de milenio. Las narrativas de las que se componen ambas películas revelan tanto las huellas de la violencia del conflicto armado interno y las múltiples crisis que marcaron esos años como las dimensiones menos exploradas del resurgimiento económico neoliberal. En segundo lugar, un registro visual que medita acerca de la conversión de la vida en superficie - despojada de cualquier significado más allá de la supervivencia, relegada, expuestay del lugar de la descomposición y la materia en este contexto, el cual, a partir de aquí, se proyecta hacia un futuro por demás incierto. Es desde esta doble relación (histórica y visual) que se produce una verdadera puesta en escena que logra visibilizar lo precario como mecanismo de anclaje inevitable de la subjetividad de las clases populares del país. 


\section{REFERENCIAS}

Agamben, G. (2013). Homo sacer: el poder soberano y la nuda vida (Trad. A. G. Cuspinera). Valencia, España: Pre-textos.

Appadurai, A. (Ed.). (1986). The social life of things: Commodities in cultural perspective. Cambridge, Reino Unido: Cambridge University Press.

Avelar, I. (2009). History, neurosis, and subjectivity: Gustavo Ferreyra's rewriting of neoliberal ruins. En M. J. Lazzara y V. Unruh (Eds.), Telling ruins in Latin America (pp. 183-193). Nueva York, Estados Unidos de América: Palgrave Macmillan.

Beerekamp, H. (2012). The eternal outsider. Introducing Heddy Honigman's ouvre. En Heddy Honigmann in focus. 6 DVDs + book. Hilversum, Países Bajos: Nederlands Instituut voor.

Benjamin, W. (2009). Para una crítica de la violencia (Trads. J. Fava y T. Bartoletti). En M. Vedda (Ed.), Estética y política (pp. 31-64). Buenos Aires, Argentina: Las cuarenta.

Bennett, J. (2015). Systems and things: On vital materialism and object-oriented philosophy. En R. Grusin (Ed.), The nonhuman turn (pp. 223-240). Mineápolis, Estados Unidos de América: University of Minnesota Press.

Burucúa, C. y Sitnisky, C. (2018). Introduction: Forms of the precarious in the cinemas of the Americas. En C. Burucúa y C. Sitnisky (Eds.), The precarious in the cinemas of the Americas (pp. 1-15). Basingstoke, Reino Unido: Palgrave Macmillan.

Butler, J. (1997). The psychic life of power: Theories in subjection. Stanford, Estados Unidos de América: Stanford University Press.
Butler, J. (2006). Precarious life: The powers of mourning and violence (2. ${ }^{\mathrm{a}}$ ed.). Londres, Reino Unido: Verso.

Calero, J. (2011). Una impecable saudade: el cine de Heddy Honigmann. Recuperado de https://www.cinencuentro. com/2011/03/12/una-impecable-saudade-cine-heddy-honigmann/

Comisión de la Verdad y Reconciliación. (2003). Informe Final. Recuperado de http://www.cverdad.org.pe/ifinal/ index.php

Daly, T. (2018). Beyond human: Vital materialisms in the Andean avant-gardes. Lewisburg, Estados Unidos de América: Bucknell University Press.

Furtado, G. P. (2016). Where are the «people»?: The politics of the virtual and the ordinary in contemporary Brazilian documentaries. En M. G. Arenillas y M. J. Lazzara (Eds.), Latin American documentary film in the new millennium (pp. 115-131). Nueva York, Estados Unidos de América: Palgrave Macmillan.

Godoy, M. (2013). $180^{\circ}$ gira mi cámara. Lo autobiográfico en el documental peruano. Lima, Perú: PUCP, Departamento Académico de Comunicaciones.

Honigmann, H. (Directora) y Van Voorst, S. (Productora). (1994). Metal y melancolía [Película]. Países Bajos: Ariel Film y VPRO Televisión.

Honigmann, H. (Directora) y Cobos, C. (Productora). (2008). El olvido [Película]. Países Bajos: Cobos Films, Ikon y ZDF/Art.

Hoyos, H. (2016). La cultura material en las literaturas y culturas iberoamericanas de hoy. Cuadernos de Literatura, 20(40), 254-261. https://doi. org/10.11144/javeriana.cl20-40.cmlc 
Mesquita Duarte, M. (2017). Reading history through film: Cinema, memory, and the persistence of time in Heddy Honigmann's Forever (2006). Studies in Documentary Film, 12(1), 56-71. https://doi.org/10.1080/17503280.2017. 1420415

Morton, T. (2015). They are here. En R. Grusin (Ed.), The nonhuman turn (pp. 167192). Mineápolis, Estados Unidos de América: University of Minnesota Press.

Nancy, J. (1991). Introduction. En E. Cadava, P. Connor y J. Nancy (Eds.), Who comes after the subject? (pp. 1-8). Nueva York, Estados Unidos de América: Routledge.

Otra Mirada. (febrero, 2013). De la jungla al orden, el transporte en Lima. Otra Mirada. Análisis y propuestas de política, 21. Recuperado de http://www. otramirada.pe/sites/default/files/ documentos/om_21.pdf

Ruffinelli, J. (2009). El olvido. En P. A. Paranaguá (Ed.), Olhares desinibidos: $O$ novo documentário ibero-americano 2000/2008 = Miradas desinhibidas: El nuevo documental iberoamericano 2000/2008 (pp. 170-177). Madrid, España: Sociedad Estatal de Conmemoraciones Culturales.

Sesic, R. (2013). Heddy Honigmann. En The concise Routledge encyclopedia of the documentary film (pp. 369-370). Nueva York, Estados Unidos de América: Routledge. 